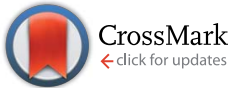

Cite this: RSC Adv., 2016, 6, 46089
Received 17th March 2016 Accepted 3rd May 2016

DOI: $10.1039 / c 6 r a 07088 d$

www.rsc.org/advances

\section{Electrospinning of polymer-free cyclodextrin/ geraniol-inclusion complex nanofibers: enhanced shelf-life of geraniol with antibacterial and antioxidant properties $\dagger$}

\author{
Zeynep Aytac, ${ }^{\text {ab }}$ Zehra Irem Yildiz, ${ }^{\text {ab }}$ Fatma Kayaci-Senirmak, ${ }^{\text {ab }}$ Nalan Oya San \\ Keskin, ${ }^{\text {cd }}$ Turgay Tekinayde and Tamer Uyar ${ }^{\star a b}$
}

\begin{abstract}
Free-standing nanofibrous webs of cyclodextrin/geraniol-inclusion complex (CD/geraniol-IC-NF) showing antibacterial, antioxidant activity and slow release of geraniol were developed as flavour/ fragrance releasing materials via electrospinning. The electrospinning of CD/geraniol-IC-NFs with uniform and bead-free morphology was achieved without using a polymer matrix. Three types of CDs modified with hydroxypropyl and methyl groups (HPBCD, M $\beta C D$, and $H P \gamma C D$ ) were used to obtain $\mathrm{CD}$ /geraniol-IC-NFs. The polymer-free CD/geraniol-IC-NFs allow us to attain much higher geraniol loading $(\sim 11 \%, w / w)$ when compared to electrospun polymeric nanofibers containing CD/geraniol-IC $(\sim 5 \%, w / w)$. Geraniol has a volatile nature, yet, a significant amount of geraniol ( $60-90 \%)$ was preserved in CD/geraniol-IC-NFs due to the complexation, whereas evaporation of geraniol was unavoidable for polymeric nanofibers incorporating geraniol without cyclodextrin. Short-term ( 3 h) temperature dependent release $\left(37^{\circ} \mathrm{C}, 50^{\circ} \mathrm{C}\right.$, and $75^{\circ} \mathrm{C}$ ) and long-term open air (50 days, at RT) release tests revealed that $\mathrm{M} \beta C D /$ geraniol-IC-NF released less geraniol compared to $\mathrm{HP} \beta C D /$ geraniol-IC-NF and $\mathrm{HP \gamma} C D /$ geraniol-IC-NF, indicating that much stronger inclusion complexation was formed between $M B C D$ and geraniol. The release of geraniol from CD/geraniol-IC-NFs prevented the colonization of Gram-negative (Escherichia coli) and Gram-positive (Staphylococcus aureus) bacteria to a great extent, as observed in the antibacterial activity results. It was observed that CD/geraniol-IC-NFs had higher antioxidant activity compared to pure geraniol due to the solubility increase. In brief, the results reported here may open a new door to enhance the performance of essential oils and flavour/fragrances, to preserve volatile compounds from evaporation and to better understand the potential of CD/IC-NFs as carrier systems for guest compounds in the food, cosmetic and household cleaning industries.
\end{abstract}

\section{Introduction}

Cyclodextrins (CDs) are supramolecular structures classified as cyclic oligosaccharides that are typically formed from six to eight glucopyranose units bound via $\alpha-1,4$ glycosidic linkages (Fig. 1a-c)., ${ }^{1,2}$ The hydrophobic carbon backbones of glucopyranose units form the inner walls of CDs, thus the cavity of CDs

\footnotetext{
Institute of Materials Science \& Nanotechnology, Bilkent University, Ankara 06800, Turkey. E-mail: tamer@unam.bilkent.edu.tr; Tel: +90 3122908987

${ }^{b}$ UNAM-National Nanotechnology Research Center, Bilkent University, Ankara, 06800, Turkey

${ }^{\text {'Polatl }}$ Faculty of Literature and Science, Department of Biology, Gazi University, Ankara 06900, Turkey

${ }^{d}$ Life Sciences Application and Research Center, Gazi University, Ankara 06830, Turkey ${ }^{e}$ University Faculty of Medicine, Department of Medical Biology and Genetics, Gazi University, Ankara 06560, Turkey
}

$\dagger$ Electronic supplementary information (ESI) available. See DOI: $10.1039 / \mathrm{c} 6 \mathrm{ra0} 07088 \mathrm{~d}$ is relatively hydrophobic. The unique characteristics of CDs come from their inclusion complexation ability with a variety of hydrophobic molecules owing to their hydrophobic cavity., Electrostatic interactions, van der Waals contributions, and hydrogen bonding are the driving forces of inclusion complex (IC) formation. ${ }^{1}$ CDs are more resistant to non-enzymatic hydrolysis compared to analogous linear dextrins and they are chemically stable under neutral and basic conditions. ${ }^{1}$ Another significant feature of CDs is their non-toxicity, which is why they have been used in numerous formulations of pharmaceutical products as well as in a large number of food products. ${ }^{1}$ In addition to parent CDs ( $\alpha$-CD, $\beta$-CD, and $\gamma$-CD), chemicallymodified CDs (hydroxypropyl and methylated CDs) have been synthesized to enhance the solubility, complexation ability and toxicological profiles in comparison to their parent CDs. ${ }^{1}$

Essential oils (EOs) are an important category of hydrophobic agents and they are volatile compounds characterized by a strong odour. ${ }^{3}$ Known for their antibacterial, antioxidant, 

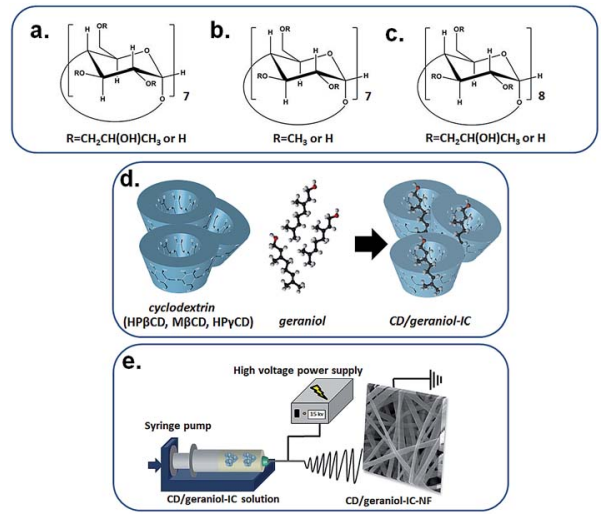

Fig. 1 The chemical structure of (a) HPBCD, (b) M $B C D$, (c) $H P \gamma C D$; the schematic representation of (d) CD/geraniol-IC formation, and (e) electrospinning of nanofibers from $\mathrm{CD} /$ geraniol- $\mathrm{IC}$ aqueous solution.

antifungal, antiseptic properties and fragrance, EOs are used in preservation and flavouring of foods and as fragrance in cosmetic and household cleaning products. ${ }^{3}$ Because of their low water solubility and highly volatile nature, encapsulation is of great importance for EOs to be used efficiently. ${ }^{3}$ Geraniol is a terpene alcohol found in EOs of various aromatic plants and it is used in cosmetics, shampoos, soaps, toiletries, household cleaners, and detergents (Fig. 1d). ${ }^{4}$ Beside its characteristic roselike odour, it also exhibits insecticidal, antimicrobial, antioxidant, antifungal and anti-inflammatory properties. ${ }^{4}$ However, its insolubility in water reduces its efficiency as flavour/ fragrance in certain applications. ${ }^{4}$ Supramolecular host-guest complexes can be designed in order to enhance the solubility of EOs with CDs. In addition to solubility issue, administering volatile compounds for various purposes often require development of novel carrier systems. One of the ways that we achieve this goal is incorporating CD-IC of active agents into electrospun polymeric nanofibers. ${ }^{5-11}$ Therefore, the need for biodegradable polymers have occurred. A number of our recent studies have dealt with the use of biodegradable/biocompatible polymeric nanofibers in encapsulating EOs. ${ }^{7-11}$

Electrospinning is one of the most common techniques to produce polymeric nanofibers. The unique characteristics of electrospun nanofibers such as high surface-to-volume ratio, controllable fiber diameter and morphologies (core-shell, hollow, and porous) can be obtained by changing the process parameters. $^{\mathbf{1 2 , 1 3}}$ The nanofiber production through electrospinning is usually carried out by dissolving polymers in organic solvents; however there exist some drawbacks like solvent costs and environmental hazards when organic solvents are used, especially in healthcare and food applications. So, the use of water-soluble polymers is an alternative choice to avoid such organic solvent issues by using water as a solvent for the electrospinning. The electrospinning of nanofibers from small molecules ${ }^{\mathbf{1 4 - 1 7}}$ and cyclic oligosaccharides such as $\mathrm{CDs}^{\mathbf{1 8 - 2 4}}$ is quite a challenge when compared to polymeric systems due to the lack of chain entanglement and overlapping. The formation self-assembly and aggregates in highly concentrated solutions of CDs via intermolecular hydrogen bonding enables the production of nanofibers from CD solutions. ${ }^{\mathbf{1 8 - 2 4}}$ Moreover, CDs are advantageous over other small molecules that are being used to produce nanofibers by electrospinning since CDs are capable of forming CD-ICs with various compounds. In our group, we had previously produced polymeric nanofibers to incorporate CD-ICs of volatile compounds such as menthol, ${ }^{5-7}$ vanillin, ${ }^{\mathbf{8}}$ eugenol, ${ }^{\mathbf{9}}$ geraniol, ${ }^{\mathbf{1 0}}$ and allyl isothiocyanate. ${ }^{\mathbf{1 1}}$ However, the weight loading of volatile compound was always limited (up to $5 \%(\mathrm{w} / \mathrm{w})$, with respect to polymer matrix) since the incorporation of higher amount of CD-IC disturbs the electrospinnability of the system to obtain uniform nanofibers. In our recent studies, we have also demonstrated the electrospinning of polymer-free nanofibers from triclosan/cyclodextrin inclusion complexes by using modified CDs (HP $\beta C D$ and $\mathrm{HP} \gamma \mathrm{CD}$ ) without using polymeric carrier matrix..$^{23,24}$

In this contribution, we have formed inclusion complexes of geraniol (which is a well-known volatile essential oil compound) with three modified CDs (HP $\beta C D, M \beta C D$, and HP $\gamma$ CD) (Fig. 1d), and we have produced free-standing CD/geraniol-IC nanofibrous web via electrospinning without using polymeric carrier matrix (Fig. 1e). The solubility improvement in geraniol by complexation was confirmed by phase solubility test. The uniform and bead-free morphology of the CD/geraniol-IC nanofibers was observed by SEM imaging. Further chemical, structural and thermal characterizations of CD/geraniol-IC nanofibers were performed by ${ }^{1} \mathrm{H}-\mathrm{NMR}$, XRD, FTIR, TGA, and DSC. The short-term temperature dependent release of geraniol from CD/geraniol-IC-NF at $37{ }^{\circ} \mathrm{C}, 50{ }^{\circ} \mathrm{C}$, and $75^{\circ} \mathrm{C}$ was examined using HS GC-MS for $3 \mathrm{~h}$, whereas the long term release of geraniol from nanofibers at room temperature was measured by TGA for 50 days. The antibacterial activity of CD/geraniol-IC nanofibers against model Gram-negative (Escherichia coli (E. coli)) and Gram-positive (Staphylococcus aureus (S. aureus)) bacteria was tested using colony counting method. Furthermore, antioxidant (AO) activity of nanofibers was monitored by 2,2-diphenyl-1-picrylhydrazyl (DPPH) radical scavenging assay.

\section{Experimental}

\subsection{Materials}

Geraniol (97\%, Sigma Aldrich), 2,2-diphenyl-1-picrylhydrazyl (DPPH, Sigma-Aldrich) methanol (extra pure, Sigma-Aldrich) and deuterated dimethylsulfoxide (DMSO-d6, deuteration degree $\min 99.8 \%$ for NMR spectroscopy, Merck), polyvinyl alcohol (PVA, $M_{\mathrm{w}} \sim 85000-146000 \mathrm{~g} \mathrm{~mol}^{-1}$, Sigma Aldrich, 87$89 \%$ hydrolyzed) were purchased and used as received without any further purification. Hydroxypropyl-beta-cyclodextrin (HPßCD), methylated-beta-cyclodextrin (MßCD), and hydroxypropyl-gamma-cyclodextrin ( $\mathrm{HP} \gamma \mathrm{CD})$ was kindly donated by Wacker Chemie (Germany). The water used in the experiments was distilled-deionized from a Millipore Milli-Q ultrapure water system.

\subsection{Preparation of the solutions}

In order to prepare the $\mathrm{CD} /$ geraniol-IC solutions; $\mathrm{HP} \beta \mathrm{CD}$, $\mathrm{M} \beta \mathrm{CD}$, and $\mathrm{HP} \gamma \mathrm{CD}(200 \%, \mathrm{w} / \mathrm{v})$ was dissolved in water and 
afterwards geraniol was added. The amount of geraniol was determined as 1 : 1 molar ratio with each CD type. The resulting solutions were stirred at room temperature (RT) for overnight. Finally, electrospinning was performed and $\mathrm{HP} \beta \mathrm{CD} /$ geraniolIC-NF, M $\beta \mathrm{CD} /$ geraniol-IC-NF, and $\mathrm{HP} \gamma \mathrm{CD} /$ geraniol-IC-NF webs were obtained. The viscosity and conductivity of CD/geraniol-IC solutions and the average fiber diameter (AFD) values of CD/geraniol-IC-NF are shown in Table 1. Electrospinning of pure CD nanofibers without geraniol (HP $\beta C D-N F, M \beta C D-N F$, and HP $\gamma$ CD-NF) were produced for comparative measurements according to our previous reports. ${ }^{18,19} 10 \%(\mathrm{w} / \mathrm{w}$, with respect to polymer) geraniol encapsulated PVA solution was prepared in aqueous solution and nanofibers (PVA/geraniol-NF) was produced via electrospinning.

\subsection{Electrospinning}

$\mathrm{CD}, \mathrm{CD} /$ geraniol-IC, and PVA/geraniol solutions were loaded into a $1 \mathrm{~mL}$ plastic syringe with metallic needle of $0.4 \mathrm{~mm}$ inner diameter. Then, the solutions were pumped at a constant rate (0.5 $\mathrm{mL} \mathrm{h}^{-1}$ ) via syringe pump (KD Scientific, KDS-101, USA). A grounded metal covered by aluminium foil placed at a distance of $10 \mathrm{~cm}$ from the needle tip was used as a collector. $15-20 \mathrm{kV}$ was applied from the high voltage power supply (AU Series, Matsusada Precision Inc., Japan). CD/geraniol-IC-NFs were kept in refrigerator until the analyses. All experiments were carried out in an enclosed Plexiglas box at $25{ }^{\circ} \mathrm{C}$ and $18 \%$ relative humidity.

\subsection{Characterizations and measurements}

Phase-solubility measurements for CDs (HP $\beta C D, M \beta C D$, and $\mathrm{HP} \gamma \mathrm{CD}$ ) and geraniol systems were performed in aqueous solution according to the method of Higuchi and Connors. ${ }^{25}$ An excess amount of geraniol was added to CD solutions and the suspensions were shaken at RT. After the equilibrium was achieved at the end of 24 hours, the suspensions were filtered through $0.45 \mu \mathrm{m}$ membrane filter and finally dilution was done with water. UV spectroscopy measurements were done at 241 $\mathrm{nm}$ (Varian, Cary 100). The experiments were carried out in triplicate and each data point is the average of the three determinations.

The viscosity measurements of $\mathrm{HP} \beta \mathrm{CD} /$ geraniol-IC, $\mathrm{M} \beta \mathrm{CD} /$ geraniol-IC, and HP $\gamma \mathrm{CD} /$ geraniol-IC solutions were performed at RT via Anton Paar Physica MCR 301 rheometer equipped with a cone/plate accessory (spindle type CP 40-2) at a constant shear rate of $100 \mathrm{~s}^{-1}$. The solution conductivity for these $\mathrm{CD} /$ geraniolIC systems was measured by Inolab ${ }^{\circledR} \mathrm{pH} /$ Cond 720 -WTW.
The morphological characterization of HP $\beta C D-N F, M \beta C D-$ NF, HP $\gamma$ CD-NF, HP $\beta C D /$ geraniol-IC-NF, M $\beta C D /$ geraniol-IC$\mathrm{NF}$, and $\mathrm{HP} \gamma \mathrm{CD} /$ geraniol-IC-NF, and PVA/geraniol-NF was examined by scanning electron microscopy (SEM, FEI - Quanta 200 FEG). The nanofibrous web samples were placed on metal stubs by using double-sided copper tape prior to taking SEM images and the samples were sputtered with $5 \mathrm{~nm}$ of $\mathrm{Au} / \mathrm{Pd}$ (PECS-682) to minimize charging problem during SEM imaging of the samples. SEM images were also used to calculate the average fiber diameter (AFD) and fiber diameter distribution of the nanofibrous webs by measuring the diameter of about 100 fibers.

The proton nuclear magnetic resonance $\left({ }^{1} \mathrm{H}-\mathrm{NMR}\right)$ spectra were recorded at $400 \mathrm{MHz}$ (Bruker DPX-400). $10 \mathrm{mg}$ of $\mathrm{HP} \beta \mathrm{CD} /$ geraniol-IC-NF, M $\beta C D /$ geraniol-IC-NF, and $\mathrm{HP} \gamma \mathrm{CD} /$ geraniolIC-NF were dissolved in $0.5 \mathrm{~mL}$ of d6-DMSO to calculate the molar ratio of CDs and geraniol in each system by integrating the peak ratio of the characteristic chemical shifts corresponding to CD and geraniol. Integration of the chemical shifts $(\delta)$ was calculated by using Mestrenova software.

Thermogravimetric analysis (TGA, TA Q500, USA) analyses were performed for geraniol, HP $\beta C D-N F, M \beta C D-N F, H P \gamma C D-$ NF, HP $\beta C D /$ geraniol-IC-NF, $\mathrm{M} \beta \mathrm{CD} /$ geraniol-IC-NF, and $\mathrm{HP} \gamma \mathrm{CD} /$ geraniol-IC-NF. TGA was conducted under nitrogen atmosphere by heating the samples from $25{ }^{\circ} \mathrm{C}$ to $450{ }^{\circ} \mathrm{C}$ at the heating rate of $20^{\circ} \mathrm{C} \mathrm{min}^{-1}$. Differential scanning calorimetry (DSC, TA Q2000, USA) analyses were performed on HP $\beta C D-N F$, M $\beta C D-N F, H P \gamma C D-N F, H P \beta C D / g e r a n i o l-I C-N F, ~ M \beta C D / g e r a-$ niol-IC-NF, and $\mathrm{HP} \gamma \mathrm{CD} /$ geraniol-IC-NF with a heating rate of $20{ }^{\circ} \mathrm{C}$ min $^{-1}$ from $25{ }^{\circ} \mathrm{C}$ to $200{ }^{\circ} \mathrm{C}$ under nitrogen flow.

$\mathrm{X}$-ray diffraction (XRD) measurements of HP $\beta C D-N F, M \beta C D-$ NF, HP $\gamma$ CD-NF, HP $\beta C D / g$ eraniol-IC-NF, M $\beta C D /$ geraniol-IC-NF, and $\mathrm{HP} \gamma \mathrm{CD} /$ geraniol-IC-NF were recorded at PANalytical X'Pert powder diffractometer using $\mathrm{Cu} K \alpha$ radiation in powder diffraction configuration and the spectra were collected in the $5-30^{\circ} 2 \theta$ range. XRD was not carried out for geraniol since it is a liquid compound at RT.

The infrared spectra of geraniol, HP $\beta C D-N F, M \beta C D-N F$, HP $\gamma$ CD-NF, HPßCD/geraniol-IC-NF, M $\beta C D /$ geraniol-IC-NF, and $\mathrm{HP}_{\gamma} \mathrm{CD} / \mathrm{g}$ eraniol-IC-NF were obtained by using a Fourier transform infrared spectrometer (FTIR) (Bruker-VERTEX 70). The samples were mixed with potassium bromide $(\mathrm{KBr})$ and pressed as pellets for the measurement. The scans (64 scans) were recorded between $4000 \mathrm{~cm}^{-1}$ and $400 \mathrm{~cm}^{-1}$ at resolution of $4 \mathrm{~cm}^{-1}$.

The amount of geraniol released from $\mathrm{HP} \beta \mathrm{CD} /$ geraniol-IC$\mathrm{NF}, \mathrm{M} \beta \mathrm{CD} /$ geraniol-IC-NF, and $\mathrm{HP} \gamma \mathrm{CD} /$ geraniol-IC-NF was

Table 1 The properties of the solutions used for electrospinning and morphological characteristics of the resulting nanofibers

\begin{tabular}{|c|c|c|c|c|c|c|}
\hline Solutions & $\begin{array}{l}\% \mathrm{CD}^{a} \\
(\mathrm{w} / \mathrm{v})\end{array}$ & $\begin{array}{l}\% \text { geraniol }^{b} \\
(\mathrm{w} / \mathrm{w})\end{array}$ & $\begin{array}{l}\text { Viscosity } \\
\text { (Pa s) }\end{array}$ & $\begin{array}{l}\text { Conductivity } \\
\left(\mu \mathrm{S} \mathrm{cm}^{-1}\right)\end{array}$ & $\begin{array}{l}\text { Average fiber } \\
\text { diameter (nm) }\end{array}$ & $\begin{array}{l}\text { Fiber } \\
\text { morphology }\end{array}$ \\
\hline HP $\beta C D /$ geraniol-IC & 200 & 9.502 & 0.522 & 212 & $520 \pm 220$ & Bead free nanofibers \\
\hline $\mathrm{HP} \gamma \mathrm{CD} /$ geraniol-IC & 200 & 8.676 & 0.904 & 4.92 & $930 \pm 370$ & Bead free nanofibers \\
\hline
\end{tabular}

${ }^{a}$ With respect to solvent (water). ${ }^{b}$ With respect to total weight of the sample. 
determined through headspace gas chromatography-mass spectrometry (HS GC-MS, Agilent Technologies 7890A gas chromatograph equipped with 5975C mass spectrometer) for 3 h. The capillary column was HP-5MS (Hewlett-Packard, Avondale, PA) $(30 \mathrm{~m} \times 0.25 \mathrm{~mm}$ i.d., $0.25 \mathrm{~m}$ film thickness $)$. CD/geraniol-IC-NFs (10 mg) were placed in $20 \mathrm{~mL}$ headspace glass vials and the vial was agitated at $500 \mathrm{rpm}$ and $37^{\circ} \mathrm{C}, 50{ }^{\circ} \mathrm{C}$, and $75^{\circ} \mathrm{C}$. The release experiments were carried out in triplicate and the results were reported as average \pm standard deviation. The syringe temperature was $37^{\circ} \mathrm{C}, 50{ }^{\circ} \mathrm{C}$, and $75^{\circ} \mathrm{C}$ as well. The vapour which was injected by headspace injector from vial to $\mathrm{HS}$ GC-MS was $250 \mu \mathrm{L}$. The oven temperature was initially held at $40{ }^{\circ} \mathrm{C}$ for $3 \mathrm{~min}$. Then the temperature was raised with a gradient of $10^{\circ} \mathrm{C} \mathrm{min}{ }^{-1}$ until $200{ }^{\circ} \mathrm{C}$. The oven was held for 3 min at $200{ }^{\circ} \mathrm{C}$. The instrument was operated in a splitless and selected ion monitoring mode (SIM). NIST MS Search 2.0 library was used to decide the geraniol peak.

In order to evaluate the long term release of $\mathrm{HP} \beta \mathrm{CD} /$ geraniol-IC-NF, $\mathrm{M} \beta \mathrm{CD} /$ geraniol-IC-NF, $\mathrm{HP} \gamma \mathrm{CD} /$ geraniol-IC-NF, and PVA/geraniol-NF were kept separately at room temperature and $18 \%$ relative humidity for 50 days in open air in the laboratory. Then, TGA measurements were done at predetermined time intervals (1st day, 25th day, and 50th day).

The antibacterial properties of the HP $\beta C D /$ geraniol-IC-NF, $\mathrm{M} \beta \mathrm{CD} /$ geraniol-IC-NF, and $\mathrm{HP} \gamma \mathrm{CD} /$ geraniol-IC-NF were evaluated against Escherichia coli (E. coli, ATCC 10536) and Staphylococcus aureus (S. aureus, ATCC 25923) bacteria by using colony counting method. Prior to use, exponentially growing cultures of $E$. coli, and $S$. aureus were obtained by allowing each strain to grow in nutrient broth medium at $37^{\circ} \mathrm{C}$ for $24 \mathrm{~h}$. After bacterial activation, UV sterilized nanofibers were immersed into the culture suspension and incubated at $37{ }^{\circ} \mathrm{C}$ for $24 \mathrm{~h}$. Finally, inocula were prepared by diluting the exponentially growing cultures with physiological solution ( $0.9 \%$ sodium chloride) to obtain approximately $10^{8}$ colony forming unit (cfu $\mathrm{mL}^{-1}$ ). Different dilutions $\left(10^{1}\right.$ to $\left.10^{9}\right)$ were made by successively adding $1 \mathrm{~mL}$ culture into $9 \mathrm{~mL}$ of phosphate buffer solution. Then, $0.1 \mathrm{~mL}$ of the diluted culture was spread on a nutrient agar plate and incubated at $37^{\circ} \mathrm{C}$ for $24 \mathrm{~h}$. The number of the colonies was counted and three repeats were performed for each sample.

The antibacterial activity of the CD/geraniol-IC-NFs was defined as follows:

$$
\text { Antibacterial activity }(\%)=(A-B) / A \times 100
$$

where $A$ and $B$ are the number of colonies ( $\mathrm{cfu} \mathrm{mL}^{-1}$ ) before and after $\mathrm{CD} /$ geraniol-IC-NF were added, respectively.

Antioxidant (AO) activity of geraniol, HP $\beta C D-N F, M \beta C D-N F$, HP $\gamma$ CD-NF, HP $\beta C D / g$ geraniol-IC-NF, $M \beta C D /$ geraniol-IC-NF, and $\mathrm{HP} \gamma \mathrm{CD} / \mathrm{geraniol}-\mathrm{IC}-\mathrm{NF}$ were tested according to 2,2diphenyl-1-picrylhydrazyl (DPPH) radical scavenging assay. $10^{-4} \mathrm{M}$ DPPH solution was prepared by dissolving DPPH in methanol : water (1: 1). 40 mg HP $\beta C D-N F$, M $\beta C D-N F, ~ H P \gamma C D-$ NF, HP $\beta C D /$ geraniol-IC-NF, $\mathrm{M} \beta \mathrm{CD} /$ geraniol-IC-NF, and $\mathrm{HP} \gamma \mathrm{CD} /$ geraniol-IC-NF and $4.76 \mathrm{mg}$ geraniol (which is the maximum amount in CD/geraniol-IC-NFs) were immersed in $3 \mathrm{~mL}$ of DPPH solution. The resulting solutions were incubated in dark at RT for $72 \mathrm{~h}$. The absorbance of the solutions was measured ( $24 \mathrm{~h}, 48 \mathrm{~h}$, and $72 \mathrm{~h}$ ) via UV-Vis spectroscopy (Varian, Cary 100) at $525 \mathrm{~nm}$. The absorbance of DPPH solution was defined as $100 \%$ and the AO activities (\%) of each system were calculated with the following equation:

Antioxidant activity $(\%)=\left(A_{\text {control }}-A_{\text {sample }}\right) / A_{\text {control }} \times 100(2)$

where $A_{\text {control }}$ and $A_{\text {sample }}$ represent the absorbance of DPPH solution and DPPH solution with samples, respectively. The photographs of the solutions were taken after $24 \mathrm{~h}, 48 \mathrm{~h}$, and $72 \mathrm{~h}$ of the incubation. The experiments were performed in triplicate and the results were given as average values \pm standard deviation.

\section{Results and discussion}

\subsection{Phase solubility studies}

Phase solubility profiles of $\mathrm{HP} \beta \mathrm{CD} /$ geraniol, $\mathrm{M} \beta \mathrm{CD} /$ geraniol, and $\mathrm{HP} \gamma \mathrm{CD} /$ geraniol systems are given in Fig. 2a-c. As seen from the diagrams, the aqueous solubility of geraniol increased linearly by complexation. CD/geraniol systems exhibited $A_{\mathrm{L}}$ type diagram which is also indication of $1: 1$ stoichiometry between each CD and geraniol.

\subsection{Morphology analysis of nanofibers}

Fig. 3a-f shows scanning electron microscopy (SEM) images of HP $\beta C D-N F, \quad M \beta C D-N F, \quad H P \gamma C D-N F, H P \beta C D / g e r a n i o l-I C-N F$, $\mathrm{M} \beta \mathrm{CD} /$ geraniol-IC-NF, and $\mathrm{HP} \gamma \mathrm{CD} /$ geraniol-IC-NF. SEM image of PVA/geraniol-NF is shown in ESI Fig. S1. $\dagger$ Bead-free and uniform nanofibers were obtained as seen from SEM images. The average fiber diameter (AFD) of HP $\beta C D-N F, M \beta C D-$ NF, HP $\gamma$ CD-NF, HP $\beta C D$ /geraniol-IC-NF, M $\beta C D /$ geraniol-IC-NF, and $\mathrm{HP} \gamma \mathrm{CD} /$ geraniol-IC-NF were calculated as $910 \pm 510 \mathrm{~nm}$, $845 \pm 425 \mathrm{~nm}, 1640 \pm 545 \mathrm{~nm}, 520 \pm 220 \mathrm{~nm}, 600 \pm 220 \mathrm{~nm}$, and $930 \pm 370 \mathrm{~nm}$ from SEM images, respectively. There is no significant difference between AFDs of $\mathrm{HP} \beta \mathrm{CD} /$ geraniol-IC-NF and $\mathrm{M} \beta \mathrm{CD} /$ geraniol-IC-NF. The viscosity of $\mathrm{HP} \gamma \mathrm{CD} /$ geraniolIC solutions was higher than $\mathrm{HP} \beta \mathrm{CD} /$ geraniol-IC and $\mathrm{M} \beta \mathrm{CD} /$ geraniol-IC solutions; whereas $\mathrm{HP} \gamma \mathrm{CD} /$ geraniol-IC solutions exhibited lowest conductivity among all solutions (Table 1). Therefore, AFD of HP $\gamma \mathrm{CD} /$ geraniol-IC-NF was highest among all CD/geraniol-IC-NFs due to higher solution viscosity and much lower solution conductivity which results in less stretching of the jet during electrospinning. ${ }^{12,13}$ Furthermore, the photographs of free-standing HP $\beta C D-N F, M \beta C D-N F$, HP $\gamma$ CD-NF, HP $\beta C D /$ geraniol-IC-NF, $M \beta C D /$ geraniol-IC-NF, and $\mathrm{HP} \gamma \mathrm{CD} /$ geraniol-IC-NF webs which can be easily-handled showed that all CD/geraniol-IC-NF webs have mechanical integrity despite their main components were amorphous small molecules (Fig. 3g-f).

\subsection{The molar ratio of $\mathrm{C} / \mathrm{D}$ geraniol-Cl}

Proton nuclear magnetic resonance $\left({ }^{1} \mathrm{H}-\mathrm{NMR}\right)$ was employed to further explore the molar ratio of $\mathrm{HP} \beta \mathrm{CD} /$ geraniol-IC-NF, $\mathrm{M} \beta \mathrm{CD}$ /geraniol-IC-NF, and $\mathrm{HP} \gamma \mathrm{CD} /$ geraniol-IC-NF (Fig. 4a-c). 


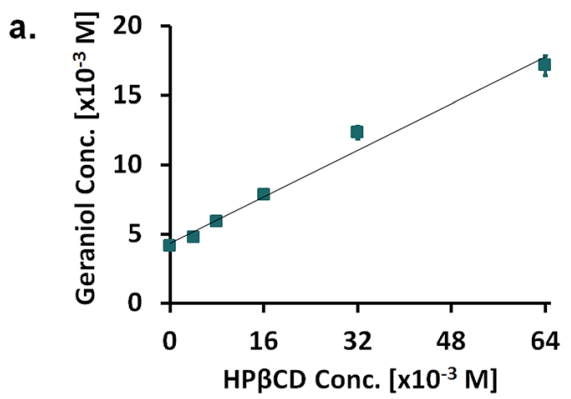

b.
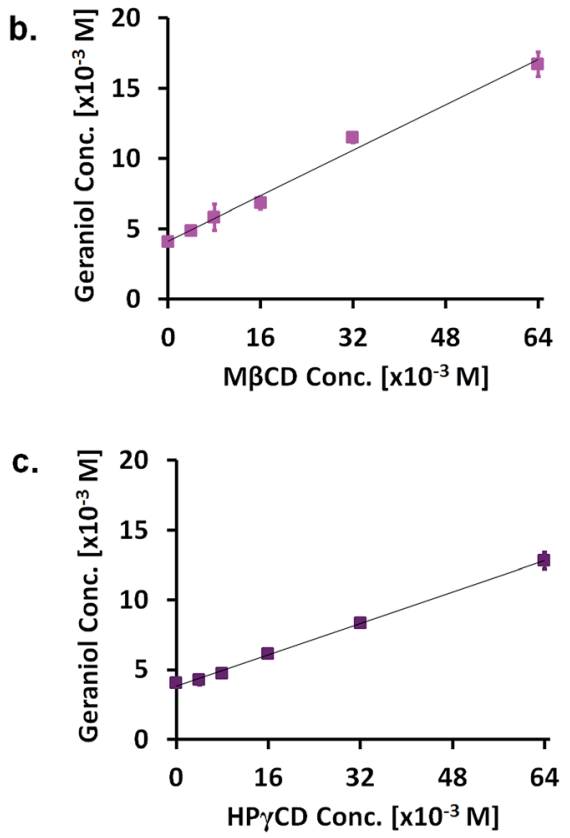

Fig. 2 Phase solubility diagram of (a) HPßCD/geraniol, (b) M $\beta C D$ / geraniol, (c) HPrCD/geraniol systems in water $(n=3)$.

In order to make the molar ratio calculations, the integration of peak at $1.0 \mathrm{ppm}(\mathrm{HP} \beta \mathrm{CD}$ and $\mathrm{HP} \gamma \mathrm{CD}$ ) and $2.0 \mathrm{ppm}$ (geraniol) were used. The molar ratio was calculated as $1.00: 0.60$ and $1.00: 0.65$ for $\mathrm{HP} \beta \mathrm{CD} /$ geraniol-IC-NF and $\mathrm{HP} \gamma \mathrm{CD} /$ geraniol-IC$\mathrm{NF}$, respectively. The molar ratio of $\mathrm{M} \beta \mathrm{CD}$ : geraniol in $\mathrm{M} \beta \mathrm{CD} /$ geraniol-IC-NF was calculated as $1.00: 0.64$ by taking the integration of the protons of $\mathrm{M} \beta \mathrm{CD}$ at $3.5-3.7 \mathrm{ppm}$ and geraniol at $2.0 \mathrm{ppm}$. From the ${ }^{1} \mathrm{H}-\mathrm{NMR}$ results, it can be concluded that the substantial amount of geraniol was preserved in $\mathrm{HP} \beta \mathrm{CD} /$ gera-

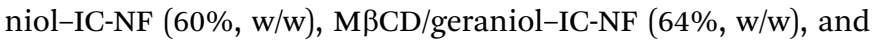
$\mathrm{HP} \gamma \mathrm{CD} /$ geraniol-IC-NF $(65 \%, \mathrm{w} / \mathrm{w})$ during the preparation, electrospinning and storage. It is worth mentioning that, in our long term release study, we have seen that geraniol could not be preserved when electrospun with polyvinyl alcohol (PVA) polymeric matrix without cyclodextrins.

\subsection{Thermal analysis of nanofibers}

The thermal stability of geraniol, HP $\beta C D-N F$, M $\beta C D-N F$, HP $\gamma$ CD-NF, HP $\beta C D /$ geraniol-IC-NF, M $\beta C D /$ geraniol-IC-NF, and $\mathrm{HP} \gamma \mathrm{CD} /$ geraniol-IC-NF were investigated by thermal gravimetric analysis (TGA) (Fig. 5a-c). Pristine HPßCD-NF,

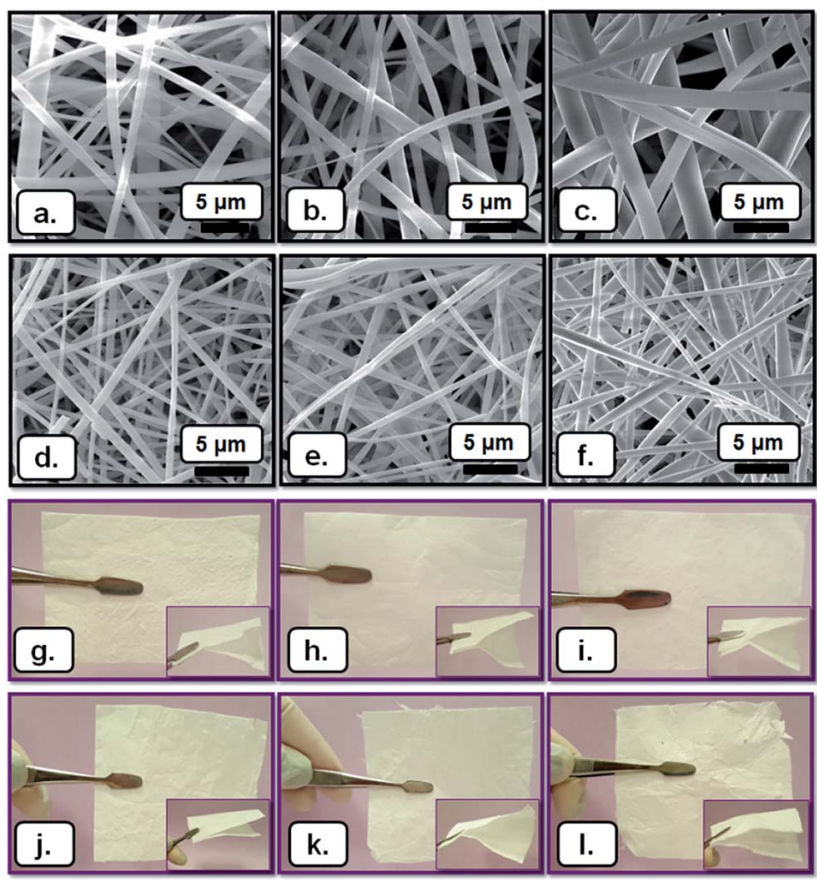

Fig. 3 SEM images of electrospun nanofibers obtained from the

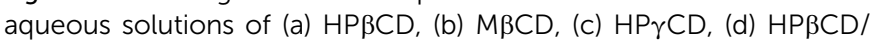
geraniol-IC, (e) $M \beta C D / g e r a n i o l-I C$, and (f) $H P \gamma C D / g e r a n i o l-I C$; the

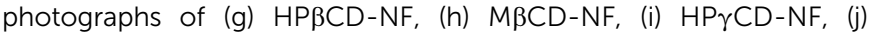
$\mathrm{HP \beta CD} /$ geraniol-IC-NF, (k) M $\beta C D /$ geraniol-IC-NF, and (l) $\mathrm{HP \gamma CD} /$ geraniol-IC-NF webs.

M $\beta C D-N F$ and HP $\gamma$ CD-NF exhibited two weight losses below $100{ }^{\circ} \mathrm{C}$ and above $275{ }^{\circ} \mathrm{C}$ which belong to the water loss and main thermal degradation of cyclodextrins (CDs), respectively. ${ }^{23}$ The first weight loss below $100^{\circ} \mathrm{C}$ observed in $\mathrm{HP} \beta \mathrm{CD} /$ geraniolIC-NF, M $\beta C D /$ geraniol-IC-NF, and $\mathrm{HP} \gamma \mathrm{CD} /$ geraniol-IC-NF attributed to water loss. In addition to water loss, two additional weight losses were seen in HP $\beta \mathrm{CD} /$ geraniol-IC-NF and $\mathrm{HP} \gamma \mathrm{CD} /$ geraniol-IC-NF. The second weight loss in HP $\beta \mathrm{CD} /$ geraniol-IC-NF was between $75{ }^{\circ} \mathrm{C}$ and $240{ }^{\circ} \mathrm{C}$; whereas the second weight loss for $\mathrm{HP} \gamma \mathrm{CD} /$ geraniol-IC-NF started from $95{ }^{\circ} \mathrm{C}$ and continued till $250{ }^{\circ} \mathrm{C}$. The shifting of thermal evaporation onset of geraniol from $70{ }^{\circ} \mathrm{C}$ to higher temperature suggested the existence of inclusion complex between CDs ( $\mathrm{HP} \beta \mathrm{CD}$ and $\mathrm{HP} \gamma \mathrm{CD}$ ) and geraniol. The third weight loss in $\mathrm{HP} \beta \mathrm{CD} /$ geraniol-IC-NF and $\mathrm{HP} \gamma \mathrm{CD} /$ geraniol-IC-NF which is above $275{ }^{\circ} \mathrm{C}$ belong to the main thermal degradation of CDs. $\mathrm{M} \beta \mathrm{CD} /$ geraniol-IC-NF exhibited four stages of weight loss which was below $100{ }^{\circ} \mathrm{C}, 70-170{ }^{\circ} \mathrm{C}, 170-290{ }^{\circ} \mathrm{C}$, and above $295^{\circ} \mathrm{C}$. These stages belong to water loss, evaporation of geraniol in the complex in 2 steps, the main thermal degradation of $\mathrm{M} \beta \mathrm{CD}$, respectively. There is a slight shift in the onset temperature of evaporation of geraniol as seen in the second stage and shifting to much higher temperature was observed in the third stage of TGA curve of $\mathrm{M} \beta \mathrm{CD} /$ geraniol-IC-NF. These results showed the presence of two types of complexes with a stronger interaction in the third step compared to second step. In addition, thermal stability of the complex in $\mathrm{M} \beta \mathrm{CD} /$ geraniol-IC-NF was higher compared to the complexes in 
a.

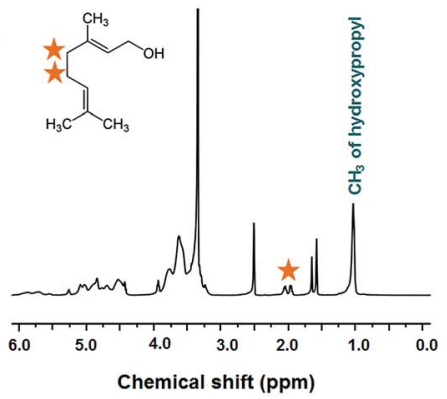

b.

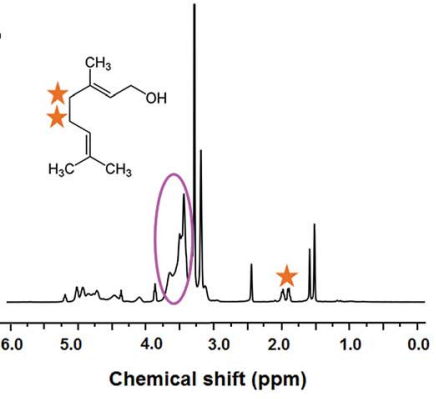

c.

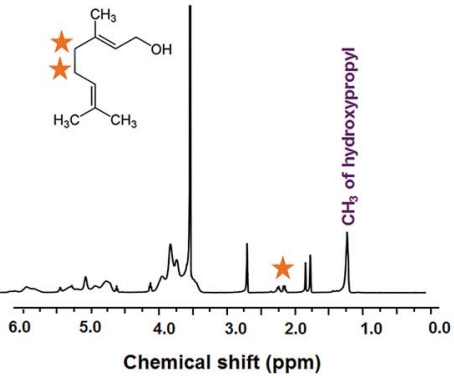

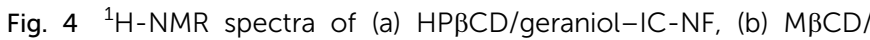
geraniol-IC-NF, and (c) $\mathrm{HPrCD} /$ geraniol-IC-NF dissolved in d6DMSO.

$\mathrm{HP} \beta \mathrm{CD} /$ geraniol-IC-NF and HP $\gamma \mathrm{CD} /$ geraniol-IC-NF and this result suggested stronger complexation between $\mathrm{M} \beta \mathrm{CD}$ and geraniol. From TGA data, the calculated geraniol amount in $\mathrm{HP} \beta \mathrm{CD} /$ geraniol-IC-NF, M $\beta \mathrm{CD} /$ geraniol-IC-NF, and $\mathrm{HP} \gamma \mathrm{CD} /$ geraniol-IC-NF was found to be $83 \%, 89 \%$, and $82 \%$ of the initial amount of geraniol, respectively. Accordingly, the molar ratio of $\mathrm{HP} \beta \mathrm{CD}, \mathrm{M} \beta \mathrm{CD}$, and $\mathrm{HP} \gamma \mathrm{CD}$ to geraniol was calculated as $1.00: 0.83,1.00: 0.89$ and $1.00: 0.82$, respectively. The molar ratio of $\mathrm{CD}$ : geraniol in $\mathrm{CD} /$ geraniol-IC-NF samples calculated from the TGA data were not exactly same values with the data obtained from ${ }^{1} \mathrm{H}-\mathrm{NMR}$, but they were comparable indicating that significant amount of geraniol was preserved in these CD based nanofibers. On the other hand, in long term release study, we observed that geraniol could not be preserved in electrospun polymeric nanofiber (PVA) without CD-IC.

Differential scanning calorimetry (DSC) curves of $\mathrm{HP} \beta C D$ NF, M $\beta C D-N F, ~ H P \gamma C D-N F, ~ H P \beta C D / g e r a n i o l-I C-N F, ~ M \beta C D /$ geraniol-IC-NF, and $\mathrm{HP} \gamma \mathrm{CD} /$ geraniol-IC-NF are given in Fig. $6 \mathrm{a}$. HP $\beta C D-N F, M \beta C D-N F$, and HP $\gamma$ CD-NF exhibited typical broad endothermic peaks between 25 and $160{ }^{\circ} \mathrm{C}, 25-155{ }^{\circ} \mathrm{C}$, and
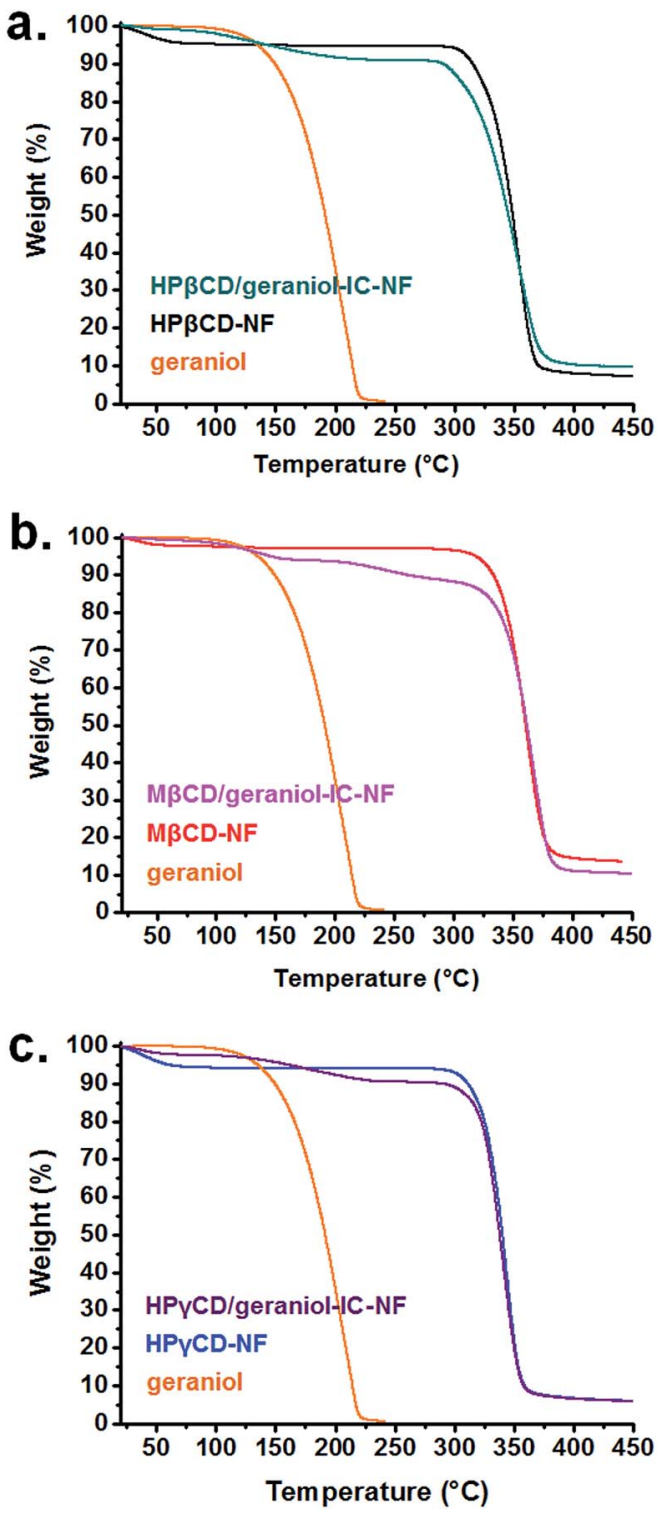

Fig. 5 TGA thermograms of (a) geraniol, HPßCD-NF, HPßCD/geraniol-IC-NF; (b) geraniol, MBCD-NF, MBCD/geraniol-IC-NF; (c) geraniol, HPrCD-NF, HPrCD/geraniol-IC-NF.

25-155 ${ }^{\circ} \mathrm{C}$, respectively and these peaks correspond to the dehydration of CDs. DSC curves of CD/geraniol-IC-NF indicated endothermic peaks in the range of $65-150{ }^{\circ} \mathrm{C}, 60-150{ }^{\circ} \mathrm{C}$, and 65-170 ${ }^{\circ} \mathrm{C}$ for $\mathrm{HP} \beta \mathrm{CD} /$ geraniol-IC-NF, $\mathrm{M} \beta \mathrm{CD} /$ geraniol-IC-NF and $\mathrm{HP} \gamma \mathrm{CD} /$ geraniol-IC-NF, respectively. The enthalpies of endothermic transitions of HP $\beta C D-N F, M \beta C D-N F$, and HP $\gamma C D-$ $\mathrm{NF}$ were $329 \mathrm{~J} \mathrm{~g}^{-1}, 99 \mathrm{~J} \mathrm{~g}^{-1}$, and $255 \mathrm{~J} \mathrm{~g}^{-1}$, while the enthalpies of $\mathrm{HP} \beta \mathrm{CD} /$ geraniol-IC-NF, M $\beta \mathrm{CD} /$ geraniol-IC-NF, and $\mathrm{HP} \gamma \mathrm{CD} /$ geraniol-IC-NF were $84 \mathrm{~J} \mathrm{~g}^{-1}, 42 \mathrm{~J} \mathrm{~g}^{-1}$, and $147 \mathrm{~J} \mathrm{~g}^{-1}$, respectively. The reduction in the enthalpy of HP $\beta C D-N F, M \beta C D-N F$, and HP $\gamma \mathrm{CD}-\mathrm{NF}$ with the complexation of geraniol indicated that certain amount of water molecules in the cavity of CDs are displaced with geraniol which is an indication of complexation between CD and geraniol. ${ }^{26}$ 

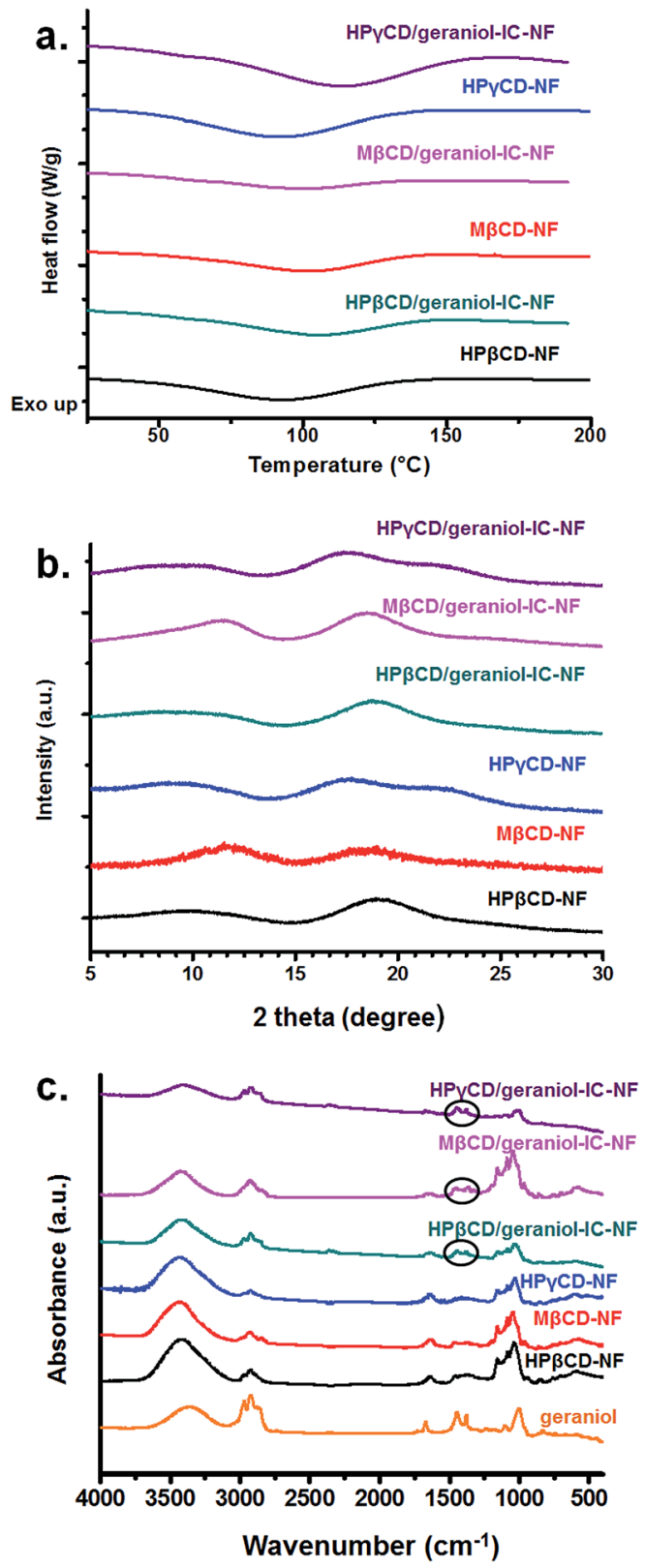

Fig. 6 (a) DSC thermograms of HPßCD-NF, HPßCD/geraniol-IC-NF, $M \beta C D-N F, M \beta C D / g e r a n i o l-I C-N F, H P \gamma C D-N F$, and HPrCD/geraniol-IC-NF; (b) XRD patterns of HPBCD-NF, M $\beta C D-N F, H P \gamma C D-N F$,

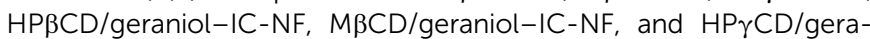
niol-IC-NF; (c) FTIR spectra of geraniol, HPBCD-NF, MBCD-NF, HPrCD-NF, HPBCD/geraniol-IC-NF, MBCD/geraniol-IC-NF, and HPrCD/geraniol-IC-NF.

\subsection{Structural characterization of nanofibers}

X-ray diffraction (XRD) patterns of HP $\beta C D-N F, M \beta C D-N F$, HP $\gamma$ CD-NF, HP $\beta C D /$ geraniol-IC-NF, $\quad M \beta C D /$ geraniol-IC-NF, and $\mathrm{HP} \gamma \mathrm{CD} /$ geraniol-IC-NF are shown in Fig. 6b. It is known that HP $\beta C D-N F$, M $\beta C D-N F$, and HP $\gamma$ CD-NF are amorphous like $\mathrm{HP} \beta \mathrm{CD}, \mathrm{M} \beta \mathrm{CD}$, and $\mathrm{HP} \gamma \mathrm{CD}$ molecules. HP $\beta \mathrm{CD} /$ geraniol-IC$\mathrm{NF}, \mathrm{M} \beta \mathrm{CD} /$ geraniol-IC-NF, and $\mathrm{HP} \gamma \mathrm{CD} /$ geraniol-IC-NF were amorphous as well. Moreover, there is no crystal formation of geraniol in $\mathrm{HP} \beta \mathrm{CD}$ /geraniol-IC-NF, $\mathrm{M} \beta \mathrm{CD} /$ geraniol-IC-NF, and
$\mathrm{HP} \gamma \mathrm{CD} /$ geraniol-IC-NF and this result confirms the formation of CD-IC.

The chemical structures of geraniol, HP $\beta C D-N F, M \beta C D-N F$, HP $\gamma$ CD-NF, HP $\beta C D / g$ eraniol-IC-NF, M $\beta C D / g e r a n i o l-I C-N F$, and $\mathrm{HP} \gamma \mathrm{CD} /$ geraniol-IC-NF was also investigated by FTIR spectroscopy (Fig. 6c). The FTIR spectrum of geraniol was characterized by absorption peaks at $3326 \mathrm{~cm}^{-1}, 1416 \mathrm{~cm}^{-1}$ (OH), $2978 \mathrm{~cm}^{-1}, 2933 \mathrm{~cm}^{-1}, 1371 \mathrm{~cm}^{-1}\left(\mathrm{CH}_{2}\right), 1650 \mathrm{~cm}^{-1}$, $1022 \mathrm{~cm}^{-1}, 946 \mathrm{~cm}^{-1}, 863 \mathrm{~cm}^{-1}$ (C=C), $1100 \mathrm{~cm}^{-1}, 1155 \mathrm{~cm}^{-1}$ (C-C-C) and $1707 \mathrm{~cm}^{-1}(\mathrm{C}-\mathrm{O}) .{ }^{27}$ The characteristic absorption peaks of pure CDs observed at around 1030, 1080, and $1157 \mathrm{~cm}^{-1}$ due to the coupled $\mathrm{C}-\mathrm{C}$ and $\mathrm{C}-\mathrm{O}$ stretching vibrations and antisymmetric stretchingvibration of the $\mathrm{C}-\mathrm{O}-\mathrm{C}$ glycosidic bridge, $1638 \mathrm{~cm}^{-1}, 2925 \mathrm{~cm}^{-1}$, and $3401 \mathrm{~cm}^{-1}$ corresponding to $\mathrm{H}-\mathrm{OH}$ bending, $\mathrm{C}-\mathrm{H}$ stretching and $\mathrm{O}-\mathrm{H}$ stretching, respectively overlap with the geraniol peaks. ${ }^{28}$ Therefore, the geraniol peaks at around $1380 \mathrm{~cm}^{-1}$ and $1450 \mathrm{~cm}^{-1}$ in CD/geraniol-IC-NFs indicated the presence of geraniol in the nanofibers. In addition, shifting of these absorption bands toward higher frequency suggested the formation of the complex between geraniol and CDs. Similar peak shifts were also reported in the literature for geraniol/CD complexes. ${ }^{27}$

\subsection{Release study}

The release results of geraniol from $\mathrm{HP} \beta \mathrm{CD} /$ geraniol-IC-NF, $\mathrm{M} \beta \mathrm{CD} /$ geraniol-IC-NF, and $\mathrm{HP} \gamma \mathrm{CD} /$ geraniol-IC-NF are depicted in Fig. 7a-c. When the temperature increases, the diffusion coefficient of the molecules increases; ${ }^{29}$ so, the amount of geraniol released from $\mathrm{HP} \beta \mathrm{CD} /$ geraniol-IC-NF, M $\beta \mathrm{CD} /$ geraniol-IC-NF, and $\mathrm{HP} \gamma \mathrm{CD} /$ geraniol-IC-NF was increased with increasing temperature from $37{ }^{\circ} \mathrm{C}$ to $75^{\circ} \mathrm{C}$. The total released amount of geraniol from $\mathrm{M} \beta \mathrm{CD} / \mathrm{g}$ eraniol-IC-NF was lower when compared to $\mathrm{HP} \beta \mathrm{CD} /$ geraniol-IC-NF and $\mathrm{HP} \gamma \mathrm{CD} /$ geraniol-IC$\mathrm{NF}$ at $37{ }^{\circ} \mathrm{C}, 50{ }^{\circ} \mathrm{C}$, and $75^{\circ} \mathrm{C}$. This correlates with the higher thermal stability of $\mathrm{M} \beta \mathrm{CD} / \mathrm{geraniol}-\mathrm{IC}-\mathrm{NF}$ as observed in TGA results (Fig. 5) when compared to $\mathrm{HP} \beta \mathrm{CD} /$ geraniol-IC-NF and $\mathrm{HP} \gamma \mathrm{CD} /$ geraniol-IC-NF. In addition, although the total amount of preserved geraniol was almost same in $\mathrm{HP} \beta \mathrm{CD} /$ geraniol-IC$\mathrm{NF}$ and $\mathrm{HP} \gamma \mathrm{CD} /$ geraniol-IC-NF as calculated from TGA results; the release amount of geraniol at $37^{\circ} \mathrm{C}, 50{ }^{\circ} \mathrm{C}$, and $75^{\circ} \mathrm{C}$ from $\mathrm{HP} \gamma \mathrm{CD} / \mathrm{geraniol}-\mathrm{IC}-\mathrm{NF}$ was much less compared to HP $\beta C D /$ geraniol-IC-NF. The reason for the less amount of geraniol released from $\mathrm{HP} \gamma \mathrm{CD} /$ geraniol-IC-NF than that of HP $\beta C D / g e r a n i o l-I C-N F$ could be the higher complexation strength between HP $\gamma \mathrm{CD}$ and geraniol.

TGA measurements were carried out in order to evaluate the long term release of $\mathrm{HP} \beta \mathrm{CD} /$ geraniol-IC-NF, $\mathrm{M} \beta \mathrm{CD} /$ geraniolIC-NF, HP $\gamma \mathrm{CD} /$ geraniol-IC-NF and geraniol encapsulated PVA nanofibers (PVA/geraniol-NF) (ESI Fig. S2 $\dagger$ ). The results are given in Table 2. Most of the geraniol did not release from $\mathrm{M} \beta \mathrm{CD} / \mathrm{g}$ eraniol-IC-NF in parallel with the short term release experiments. This might be attributed to the high thermal stability of complex formed in $\mathrm{M} \beta \mathrm{CD} /$ geraniol-IC as shown in Fig. 5b. Only $24 \%(w / w)$ of geraniol was released from $\mathrm{M} \beta \mathrm{CD} /$ geraniol-IC-NF at the end of 50 days. So, it can be concluded that $\mathrm{M} \beta \mathrm{CD} / \mathrm{geraniol}-\mathrm{IC}-\mathrm{NF}$ is a better candidate for the long 

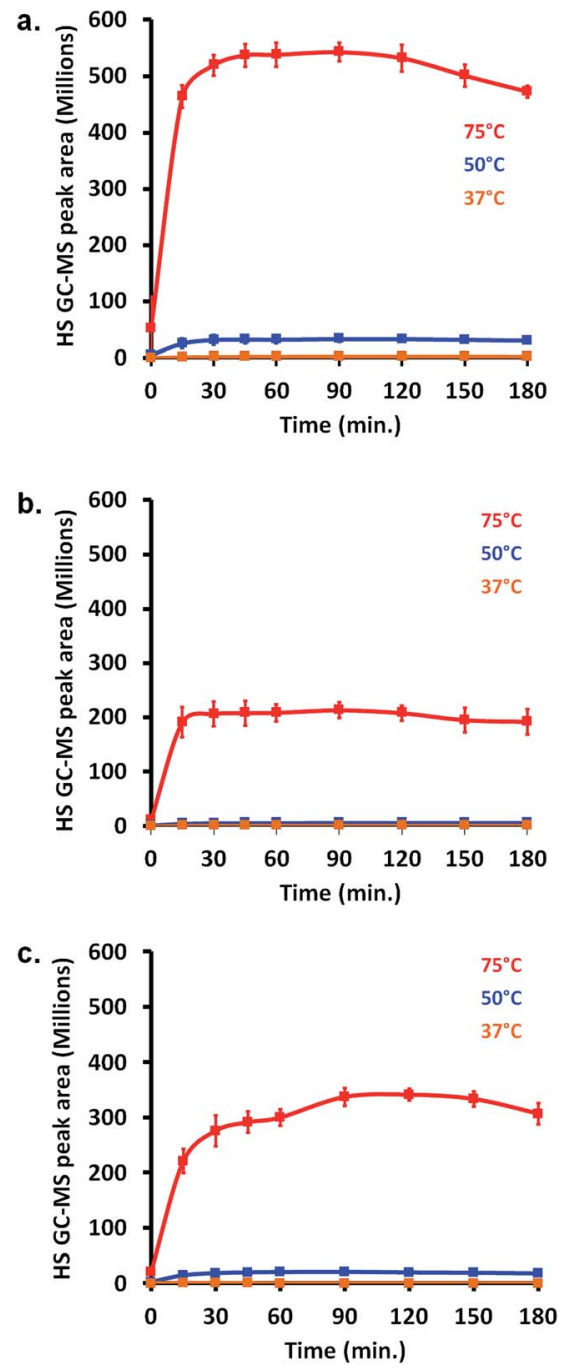

Fig. 7 The cumulative release of geraniol from (a) HP $\beta C D / g$ eraniolIC-NF, (b) M $\beta C D /$ geraniol-IC-NF, and (c) HPrCD/geraniol-IC-NF at $37^{\circ} \mathrm{C}, 50^{\circ} \mathrm{C}, 75^{\circ} \mathrm{C}(n=3)$. The error bars in the figure represent the standard deviation (SD).

term release when compared to $\mathrm{HP} \beta \mathrm{CD} /$ geraniol-IC-NF and $\mathrm{HP} \gamma \mathrm{CD} /$ geraniol-IC-NF. The amount of released geraniol was almost same for HP $\beta \mathrm{CD} /$ geraniol-IC-NF and $\mathrm{HP} \gamma \mathrm{CD} /$ geraniolIC-NF; thus, about $50 \%$ of geraniol was released from $\mathrm{HP} \beta \mathrm{CD} /$ geraniol-IC-NF and HP $\gamma \mathrm{CD} /$ geraniol-IC-NF at the end of 50 days. In our long term release study, geraniol was incorporated in PVA electrospun nanofibers for the comparative study to investigate the effect of cyclodextrin inclusion complexation for the stability of geraniol during and after electrospinning. PVA nanofiber matrix is a good comparison for CD nanofibers in terms of its electrospinnability in aqueous system and the presence of hydroxyl groups in its structure. However, we observed that geraniol could not be well preserved without CD-IC during electrospinning or during storage, and, evaporation of geraniol in PVA/geraniol-NF was unavoidable even after one day of its electrospinning. At the end of 50 days $71 \%$ of geraniol evaporated from PVA/geraniol-NF. On the contrary, here we observed that significant amount of geraniol was preserved in nanofibrous matrix of CD/geraniol-IC-NF even after a long time of storage.

\subsection{Antibacterial activity}

There are several studies in the literature about antimicrobial effect of geraniol. For example, Friedman et al. showed that geraniol was found to be bactericidal against $E$. coli $0157: \mathrm{H7}$ and Salmonella enterica. ${ }^{30}$ Further, Tampieri et al. reported the antimicrobial activity of geraniol for $S$. aureus and various fungi. ${ }^{31}$ As can be indicated from Fig. 8a-d which shows the data obtained from cfu results, prepared CD/geraniol-IC-NFs possessed strong antibacterial activity against two model bacteria (Escherichia coli (E. coli) and Staphylococcus aureus (S. aureus)). Namely, HP $\beta \mathrm{CD} /$ geraniol-IC-NF, M $\beta C D / g e r a n i o l-$ IC-NF, and HP $\gamma \mathrm{CD} /$ geraniol-IC-NF exhibited $87 \pm 0.6 \%, 100 \pm$ $0.6 \%$, and $85 \pm 0.3 \%$ and $100 \pm 0.3 \%, 100 \pm 0.8 \%, 100 \pm 0.4 \%$ antibacterial activity against $E$. coli and $S$. aureus, respectively. Antibacterial activities (\%) of CD/geraniol-IC-NFs were found to be more against $S$. aureus compared to E. coli. Gram-negative bacteria were more resistant than Gram-positive bacteria because they have an additional protective barrier of the outer membrane. $^{32}$

\subsection{Antioxidant activity}

Free radicals with one or more unpaired electrons and reactive oxygen species (ROS) including superoxide radicals, hydroxyl radicals, singlet oxygen and hydrogen peroxide cause membrane damage, decreasing membrane fluidity, leading to cancer via DNA mutation and induce oxidation of lipids. Therefore, free radicals/ROS might lead to aging, cancer, Alzheimer's disease, diabetes and asthma by causing molecular alterations in the biological systems or spoiling of foods because of the oxidation in the biomolecules. ${ }^{33,34}$ Essential oils (EOs) might have antioxidant (AO) properties and the

Table 2 The amount of geraniol in CD/geraniol-IC-NFs at room temperature for 50 days

\begin{tabular}{|c|c|c|c|c|}
\hline Samples & Theoretical amount of geraniol $^{a}(\%)$ & 1st day $(\%)$ & 25 th day $(\%)$ & 50 th day $(\%)$ \\
\hline HPßCD/geraniol-IC-NF & $9.502(100 \%)$ & $7.233(76 \%)$ & $5.258(55 \%)$ & $4.228(45 \%)$ \\
\hline $\mathrm{M} \beta \mathrm{CD} /$ geraniol-IC-NF & $11.894(100 \%)$ & $9.768(82 \%)$ & $9.381(79 \%)$ & $9.037(76 \%)$ \\
\hline PVA/geraniol-NF & $9.774(100 \%)$ & $4.415(45 \%)$ & $3.281(34 \%)$ & $2.866(29 \%)$ \\
\hline
\end{tabular}

${ }^{a}$ With respect to total weight of the sample. 
a.

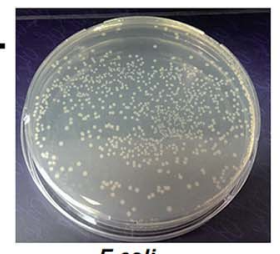

E.coli

b.

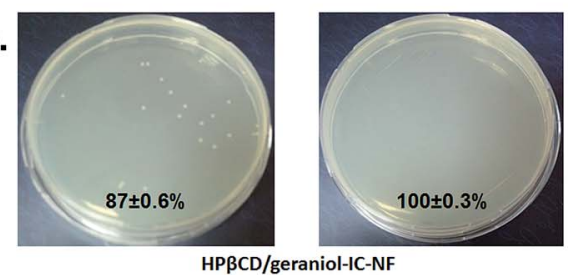

c.

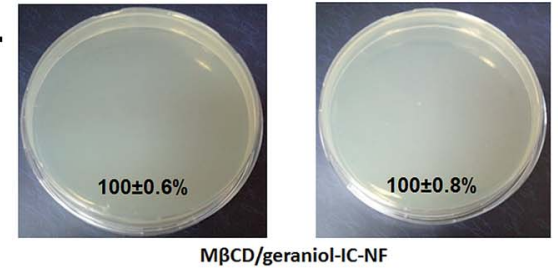

d.

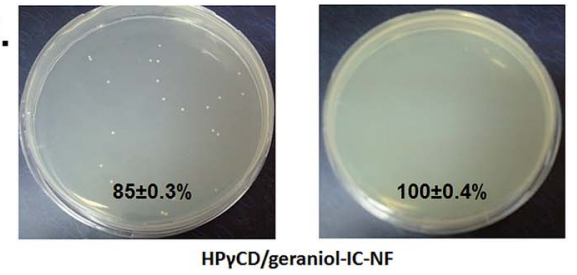

Fig. 8 (a) Exemplary images of Escherichia coli (E. coli), Staphylococcus aureus (S. aureus) colonies. The growth inhibition rate (\%) and exemplary images of $E$. coli and $S$. aureus colonies treated by (b) $\mathrm{HPBCD} /$ geraniol-IC-NF, (c) MBCD/geraniol-IC-NF, and (d) HPrCD/ geraniol-IC-NF $(n=3)$.

mechanism rely on preventing further damage of mitochondrial DNA that ultimately leading to accumulation of ROS by interacting with them. ${ }^{35}$ It has been reported that geraniol decline the lipid peroxidation and inhibit ROS generation in the cells. ${ }^{4}$ In order to prevent potential diseases and food spoilage, AO compounds are being used in various applications; so detecting the $\mathrm{AO}$ capacity of materials is of importance. There exist many methods to evaluate $\mathrm{AO}$ capacity of materials. ${ }^{36}$ However, 2,2-diphenyl-1-picrylhydrazyl (DPPH) radical scavenging assay is one of the most widely used methods to decide the potential of AO molecules to scavenge free radicals. DPPH is a stable free radical in a deep purple colour. When it interacts with an AO molecule purple colour of the solution turns into colour of hydrazine which is yellow. ${ }^{37}$

The AO activity of geraniol, HP $\beta C D-N F, M \beta C D-N F, ~ H P \gamma C D-$ $\mathrm{NF}, \quad \mathrm{HP} \beta \mathrm{CD} /$ geraniol-IC-NF, $\mathrm{M} \beta \mathrm{CD} /$ geraniol-IC-NF, and $\mathrm{HP} \gamma \mathrm{CD} /$ geraniol-IC-NF was calculated as $55 \pm 2 \%, 58 \pm 4 \%, 41$ $\pm 2 \%, 59 \pm 1 \%, 75 \pm 2 \%, 59 \pm 2 \%$, and $57 \pm 1 \%$ at the end of $72 \mathrm{~h}$, respectively. The photographs of the DPPH solutions in which geraniol, HP $\beta C D-N F$, M $\beta C D-N F, ~ H P \gamma C D-N F, ~ H P \beta C D /$ geraniol-IC-NF, M $\beta C D /$ geraniol-IC-NF, and $\mathrm{HP} \gamma \mathrm{CD} /$ geraniolIC-NF were immersed up to for $72 \mathrm{~h}$ are shown in Fig. 9. In a study of Stobiecka et al., AO activity of geraniol comparative to geranylacetone was evaluated with DPPH assay in methanol, ethanol and toluene. It was concluded that geranylacetone exhibited higher AO activity than geraniol in methanol and ethanol systems in 30 minutes. However, AO activity of both geranylacetone and geraniol was quite low due to the slow kinetics of DPPH radical-scavenging caused by the steric inaccessibility. ${ }^{38}$ In addition, it has been deduced that the reaction between DPPH and geranylacetone and geraniol was very slow irrespective of the solvent used and high amount of compound had to be applied in order to observe any measurable effects. Similarly, Zyl et al. presented that geraniol has little activity according to DPPH assay performed in methanol for $30 \mathrm{~min} .{ }^{39}$ On the contrary, Choi et al. performed DPPH assay for $30 \mathrm{~min}$ and claimed that geraniol had shown quite high AO activity $(88 \%, 236 \mathrm{mg}$ of Trolox equiv. per $\mathrm{mL}) .^{40}$ Thus, our result in which the reaction was very slow and the activity was not high as much as observed in the study of Choi et al. is agreed with the study of Stobiecka et al. and Zyl et al. HPßCD-NF, M $\beta C D-N F$ and $\mathrm{HP} \gamma \mathrm{CD}-\mathrm{NF}$ exhibited moderate AO activity due to the presence of hydroxyl groups in the structure. ${ }^{41}$ An improvement was observed in the AO activity of CD-NFs with the addition of geraniol in the system. Only $\mathrm{HP} \gamma \mathrm{CD} /$ geraniol-IC-NF showed similar AO activity with $\mathrm{HP} \gamma \mathrm{CD}-\mathrm{NF}$, this might be due to higher strength of the complex and the position of geraniol in the cavity which is not allowing the donation of hydrogen from the system easily. AO activity (\%) of HP $\beta C D /$ geraniol-IC-NF was much more as compared to AO activity of geraniol, $\mathrm{M} \beta \mathrm{CD} /$ geraniol-IC-NF and $\mathrm{HP} \gamma \mathrm{CD} /$ geraniol-IC-NF. The aqueous solubility increment of geraniol as shown in phase solubility diagrams could be the reason for the better AO activity of $\mathrm{HP} \beta \mathrm{CD} /$ geraniol-IC-NF as compared with geraniol. Moreover, higher $\mathrm{AO}$ activity of $\mathrm{HP} \beta \mathrm{CD} /$ geraniol-IC-NF than $\mathrm{M} \beta \mathrm{CD} /$ geraniol-IC-NF and HP $\gamma \mathrm{CD} /$ geraniol-IC-NF might be related with the

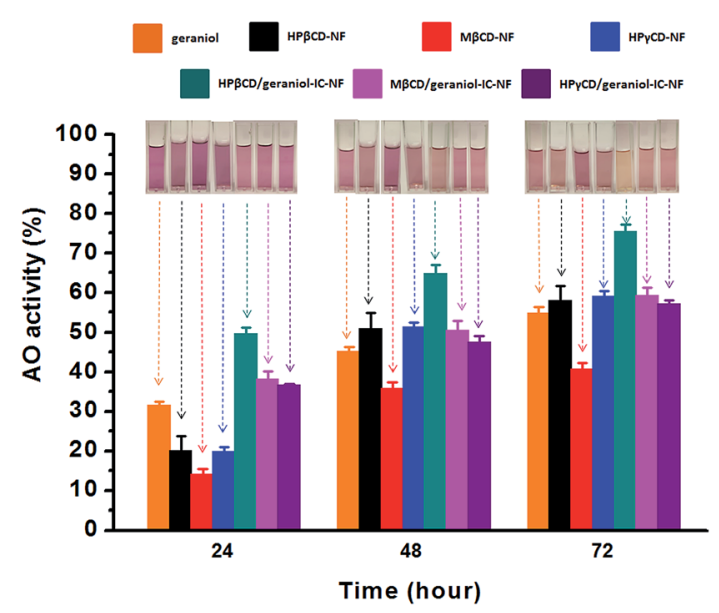

Fig. 9 The antioxidant (AO) activity (\%) of geraniol, HPßCD-NF, $M \beta C D-N F, H P \gamma C D-N F, H P \beta C D / g e r a n i o l-I C-N F, M \beta C D / g e r a n i o l-I C-$ $\mathrm{NF}$, and $\mathrm{HPrCD} /$ geraniol-IC-NF and the photographs of DPPH solutions in which geraniol, HPBCD-NF, M $\beta C D-N F, H P \gamma C D-N F, H P \beta C D /$

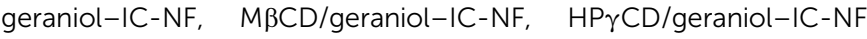
were immersed, respectively $(n=3)$. The error bars in the figure represent the standard deviation (SD). 
higher strength of the complexes formed with M $\beta C D$ and $\mathrm{HP} \gamma \mathrm{CD}$ that is inhibiting the release of geraniol and the orientation of geraniol in the cavity of CDs which might make hydrogen donation difficult. The colour of the solution in which HPßCD/geraniol-ICNF was immersed turned from purple to yellowish at the end of 72 h. So, DPPH molecules in that solution converted into diphenylpicrylhydrazine (DPPH-H). ${ }^{\mathbf{4 2}}$

\section{Conclusions}

Free-standing nanofibrous webs of geraniol/cyclodextrininclusion complexes (CD/geraniol-IC-NFs) were successfully produced by electrospinning without using a polymeric carrier matrix. We have obtained bead-free and uniform nanofibers from these non-polymeric systems of CD/geraniol-ICs for three different types of CDs (HP $\beta C D, M \beta C D$, and HP $\gamma C D)$. After electrospinning, significant amount of geraniol ( $\sim 60-90 \%)$ was well preserved by $\mathrm{CD} /$ geraniol-IC-NFs due to the inclusion complexation ability of CDs. The short-term $(3 \mathrm{~h})$ temperature dependent release $\left(37^{\circ} \mathrm{C}, 50{ }^{\circ} \mathrm{C}\right.$, and $\left.75^{\circ} \mathrm{C}\right)$ and long-term open air (50 days, at RT) release tests for geraniol from CD/geraniolIC-NFs were performed. Much less amount of geraniol was released from $\mathrm{M} \beta \mathrm{CD} / \mathrm{geraniol}-\mathrm{IC}-\mathrm{NF}$ when compared to $\mathrm{HP} \beta \mathrm{CD} /$ geraniol-IC-NF and $\mathrm{HP} \gamma \mathrm{CD} /$ geraniol-IC-NF in shortterm temperature release and long-term open air release tests, which indicated that $\mathrm{M} \beta \mathrm{CD} /$ geraniol-IC-NF was the most stable inclusion complex among the three CD/geraniol-IC-NFs web samples. The antibacterial activity test results of $\mathrm{CD} /$ geraniolIC-NFs proved quite high antibacterial activity of geraniol against Gram-negative (Escherichia coli (E. coli)) and Grampositive (Staphylococcus aureus (S. aureus)) bacteria. Moreover, CD/geraniol-IC-NFs exhibited efficient antioxidant (AO) activity when compared to pure geraniol. In brief, electrospun $\mathrm{CD} /$ geraniol-IC nanofibrous webs have shown enhanced shelflife of geraniol along with antibacterial and antioxidant properties, hence, cyclodextrin inclusion complex nanofibers with variety of flavour/fragrances may have potentials to be used as prolonged releasing systems for various applications including food, cosmetic, household, cleaning products, etc.

\section{Acknowledgements}

We would like to thank Dr Asli Celebioglu for her continuous help for the electrospinning of cyclodextrin nanofibers. Dr Uyar acknowledges The Scientific and Technological Research Council of Turkey (TUBITAK)-Turkey (Project \# 213M185) for funding this research. The Turkish Academy of Sciences - Outstanding Young Scientists Award Program (TUBA-GEBIP)-Turkey is also acknowledged for partial funding of the research. Z. Aytac, Z. I. Yildiz and F. Kayaci thank to TUBITAK-BIDEB for the PhD scholarship; and Z. Aytac and Z. I. Yildiz also thank to TUBITAK (project no. 213M185) for the PhD scholarship.

\section{Notes and references}

1 S. V. Kurkov and T. Loftsson, Int. J. Pharm., 2013, 453, 167180.
2 J. Szejtli, Chem. Rev., 1998, 98(97), 1743-1753.

3 F. Bakkali, S. Averbeck, D. Averbeck and M. Idaomar, Food Chem. Toxicol., 2008, 46, 446-475.

4 W. Chen and A. M. Viljoen, S. Afr. J. Bot., 2010, 76, 643-651.

5 T. Uyar, Y. Nur, J. Hacaloglu and F. Besenbacher, Nanotechnology, 2009, 20(12), 125703.

6 T. Uyar, J. Hacaloglu and F. Besenbacher, React. Funct. Polym., 2009, 69(3), 145-150.

7 T. Uyar, Y. Nur, J. Hacaloglu and F. Besenbacher, J. Nanosci. Nanotechnol., 2011, 11, 3949-3958.

8 F. Kayaci and T. Uyar, Food Chem., 2012, 133, 641-649.

9 F. Kayaci, Y. Ertas and T. Uyar, J. Agric. Food Chem., 2013, 61(34), 8156-8165.

10 F. Kayaci, H. S. Sen, E. Durgun and T. Uyar, Food Res. Int., 2014, 62, 424-431.

11 Z. Aytac, S. Y. Dogan, T. Tekinay and T. Uyar, Colloids Surf., B, 2014, 120, 125-131.

12 S. Ramakrishna, K. Fujihara, W. Teo, T. Lim and Z. Ma, An Introduction to Electrospinning and Nanofibers, World Scientific Publishing Company, 2005.

13 T. Uyar and F. Besenbacher, Polymer, 2008, 49, 5336.

14 M. G. McKee, J. M. Layman, M. P. Cashion and T. E. Long, Science, 2006, 311, 353-355.

15 G. Singh, A. M. Bittner, S. Loscher, N. Malinowski and K. Kern, Adv. Mater., 2008, 20, 2332-2336.

16 M. P. Cashion, X. Li, Y. Geng, M. T. Hunley and T. E. Long, Langmuir, 2010, 26, 678-683.

17 X. Yan, M. Zhou, J. Chen, X. Chi, S. Dong, M. Zhang, X. Ding, Y. Yu, S. Shaod and F. Huang, Chem. Commun., 2011, 47, 7086-7088.

18 A. Celebioglu and T. Uyar, Chem. Commun., 2010, 46(37), 6903-6905.

19 A. Celebioglu and T. Uyar, Nanoscale, 2012, 4, 621-631.

20 A. Celebioglu and T. Uyar, J. Colloid Interface Sci., 2013, 404, 1-7.

21 A. Celebioglu and T. Uyar, RSC Adv., 2013, 3, 22891-22895.

22 A. Celebioglu and T. Uyar, RSC Adv., 2013, 3, 10197-10201.

23 A. Celebioglu and T. Uyar, Langmuir, 2011, 27(10), 62186226.

24 A. Celebioglu, O. C. O. Umu, T. Tekinay and T. Uyar, Colloids Surf., B, 2014, 116, 612-619.

25 T. Higuchi and A. K. Connors, Adv. Anal. Chem. Instrum., 1965, 4, 117-212.

26 V. B. Kadam, G. S. Bamane and G. S. Raut, Int. Curr. Pharm. J., 2014, 1(1), 6-12.

27 P. P. Menezes, M. R. Serafini, B. V. Santana, R. S. Nunes, L. J. Quintans, G. F. Silva, I. A. Medeiros, M. Marchioro, B. P. Fraga, M. R. V. Santos and A. A. S. Araújo, Thermochim. Acta, 2012, 548, 45-50.

28 L. F. Chen, Q. Shen, J. P. Shen, D. T. Shi, T. Chen and H. R. Yu, Colloids Surf., A, 2012, 411, 69-73.

29 C. Y. Hu, M. Chen and Z. W. Wang, Packag. Technol. Sci., 2012, 25, 97-106.

30 M. Friedman, P. R. Henika, C. E. Levin and R. E. Mandrell, J. Agric. Food Chem., 2004, 52, 6042-6048. 
31 M. P. Tampieri, R. Galuppi, F. Macchioni, M. S. Carelle, L. Falcioni, P. L. Cioni and I. Morelli, Mycopathologia, 2005, 159, 339-345.

32 P. L. Yeagle, The Structure of Biological Membranes, CRC Press, United States, 2011.

33 A. E. Edris, Phytother. Res., 2007, 21, 308-323.

34 B. Prakash, A. Kedia, P. K. Mishra and N. K. Dubey, Food Control, 2015, 47, 381-391.

35 Y. Bhalla, V. K. Gupta and V. Jaitak, J. Sci. Food Agric., 2013, 93, 3643-3653.

36 D. Huang, B. Ou and R. L. Prior, J. Agric. Food Chem., 2005, 53, 1841-1856.
37 K. Pyrzynska and A. Pękal, Anal. Methods, 2013, 5, 42884295.

38 A. Stobiecka, Flavour Fragrance J., 2015, 30(5), 399-409.

39 R. L. Van Zyl, S. T. Seatlholo, S. F. Van Vuuren and A. M. Viljoen, J. Essent. Oil Res., 2006, 18, 129-133.

40 H. S. Choi, H. S. Song, H. Ukeda and M. Sawamura, J. Agric. Food Chem., 2000, 48(9), 4156-4161.

41 A. Corciova, C. Ciobanu, A. Poiata, C. Mircea, A. Nicolescu, M. Drobota, C. D. Varganici, T. Pinteala and N. Marangoci, J. Inclusion Phenom. Macrocyclic Chem., 2015, 81(1-2), 71-84. 42 I. Gulcin, Arch. Toxicol., 2012, 86, 345-391. 